\title{
Hybridization of Heat Pump Systems With Natural Ventilation To Improve Energy Efficiency in Cooling Dominated Buildings
}

\author{
Nuno R. Martins * (D) and Peter J. Bourne-Webb \\ CERIS, Instituto Superior Técnico, Lisboa, Portugal
}

Received: 28 June 2021 / Received in final form: 7 September 2021 / Accepted: 7 September 2021

\begin{abstract}
Building foundation piles can be used as heat exchangers in ground-source heat pump (GSHP) systems to provide highly efficient renewable heating and cooling (H\&C). Unbalanced H\&C loads lead to heat build-up in the ground, decreasing the system's overall performance. In this study, the introduction of natural ventilation $(\mathrm{NV})$ has been examined to decrease cooling load imbalance in cooling-dominated buildings to improve system efficiency. Building energy simulations estimated the H\&C loads for an office building in three Portuguese cities: Lisbon, Porto and Faro, yielding heating loads of 0.2-3.6 MWh/year and cooling loads of 260-450 MWh/year. Four renewable H\&C technology scenarios were used to assess energy performance: (1) an air-source heat pump (ASHP) system; (2) a GSHP system utilizing energy piles; (3) hybrid ASHP-NV and (4) hybrid GSHP-NV. Over 50 years of operation, in Scenario (1) COP values of 2.45-2.55 (heating) and 3.62-4.15 (cooling) were obtained. In (2), COP values increased to 4.15-4.34 (heating) but fell to $3.36-3.79$ (cooling), which increased annual final energy needs by $7-8 \%$. Unbalanced cooling loads increased the ground temperature by $21-24{ }^{\circ} \mathrm{C}$, which is unlikely to be acceptable. Compared to (1), introducing NV reduced cooling loads by $65-90 \%$ in Scenarios (3) and (4), with the final energy needs decreasing by $59-80 \%$ and $62-88 \%$, respectively. A further benefit of the GSHP-NV hybrid is that the ground temperature increase was limited to 8- $12^{\circ} \mathrm{C}$. For cooling, the COP in (3) decreased compared to (1) (3.14-3.69), while in (4), COP improved to 3.45-6.10. This study concludes that hybrid GSHP-NV systems should be considered in some cooling-dominated scenarios.
\end{abstract}

\section{Introduction}

In the modern world, people spend most of their time indoors, whether at work, at home or pursuing other activities [1], which has increased the use of energy by HVAC (heating, ventilation and air conditioning) systems. However, concern has arisen over this substantial use of energy and its consequent effect on the natural environment, which has advanced the pursuit of innovative lowenergy solutions [2].

Air-source heat pumps (ASHP) are one of the most common approaches to supply renewable heating and cooling (H\&C). This system exchanges heat with the outside air, so changes in outdoor temperature will directly affect the coefficient of performance (COP). In the ground, periodic temperature variation is low, so ground-source heat pumps (GSHP) can yield higher COPs than ASHP. However, while Life Cycle Analysis suggests GSHP are competitive, capital costs for GSHP are significantly higher

\footnotetext{
* e-mail: nunomrmartins@tecnico.ulisboa.pt
}

than those for ASHP, which hinders widespread uptake [3]. To reduce the capital cost associated with the installation of borehole heat exchangers, building foundations, especially piles (energy piles), are increasingly used. However, in the first instance, foundation piles are designed as a load bearing structural element, so their thermal behaviour is not optimized nor is their use as heat exchangers guaranteed to fully satisfy the necessary H\&C loads $[4,5]$.

Unbalanced $\mathrm{H} \& \mathrm{C}$ loads pose a particular challenge for GSHP systems. In cooling-dominated scenarios, such as commercial buildings in temperate or warm climates, this imbalance can lead to a build-up of heat in the ground, which decreases COP and increases energy consumption $[6,7]$. HVAC system hybridization can decrease that imbalance, by combining centralized HVAC and other renewable approaches, such as cooling towers [8] or dry-fluid coolers [9].

Natural ventilation (NV) can be used to decrease ventilation and cooling needs. NV utilizes airflow driven by the pressure differences that result from wind and temperature differences on one or more openings in the building envelope. Previous studies have shown that 


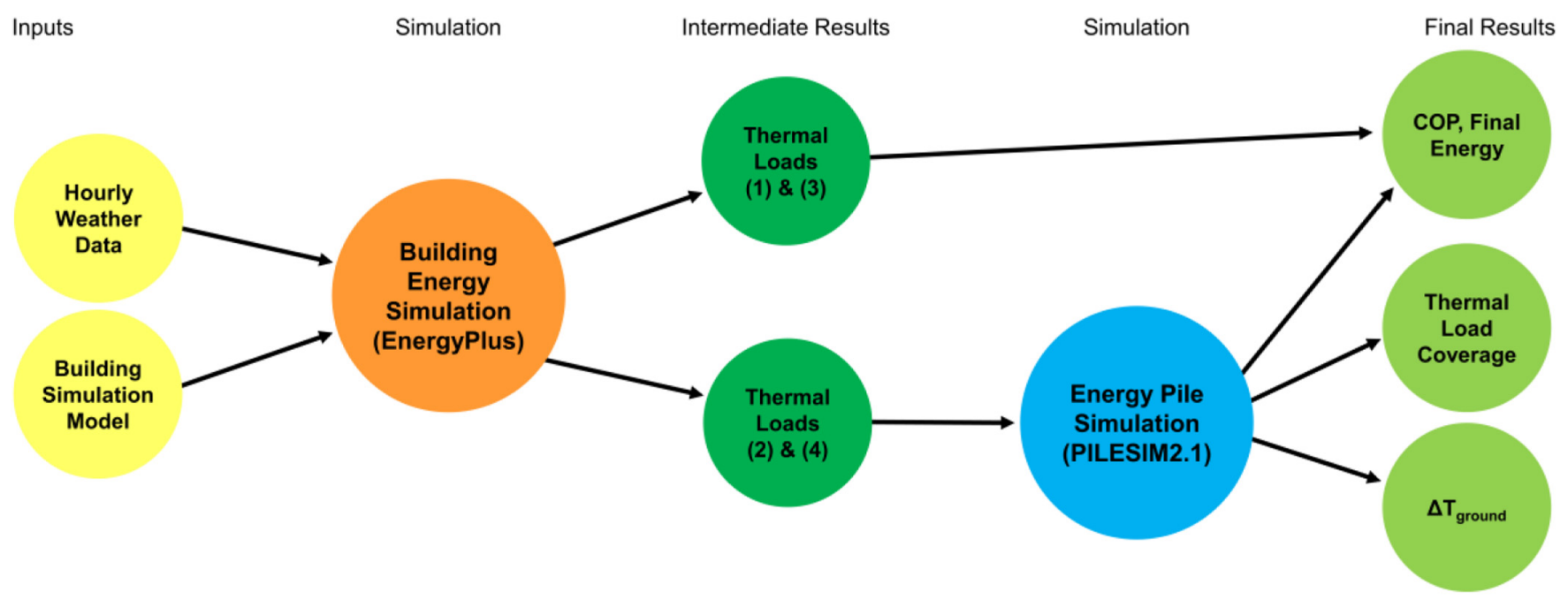

Fig. 1. Methodology diagram.

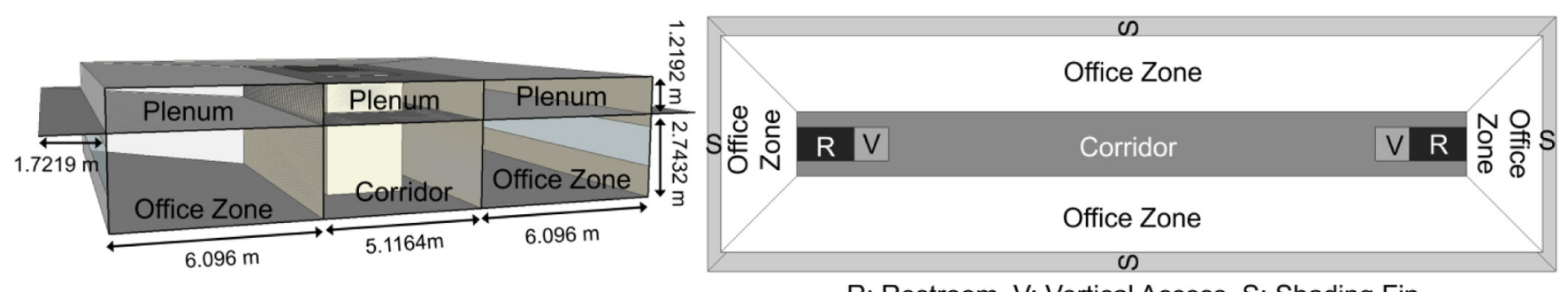

R: Restroom, V: Vertical Access, S: Shading Fin

Fig. 2. Building simulation model section cut (one floor) and simulation zones.

hybrid natural-mechanical HVAC systems can significantly decrease overall HVAC energy needs by replacing mechanical ventilation and cooling with $\mathrm{NV}$, whenever weather conditions allow its use [10-12].

In this article, a hybrid HVAC system (GSHP with piles) that uses NV is proposed. This approach's efficiency is compared, in a simulation environment, to that of other HVAC solutions for an office building model in three Portuguese cities: Lisbon, Porto and Faro.

\section{Methodology}

The methodology used in this study is presented schematically in Figure 1. EnergyPlus (shown in orange) is an open-source detailed building thermal simulation code [13] and was used to calculate thermal heating and cooling loads (in dark green) for one year, with hourly weather data and a previously validated office building model [10-12] as inputs (in yellow).

For each of the three cities, a typical mean year (TMY) weather data file was used. TMY data is generated by selecting the local weather data that is closest to the average from a dataset of several years [14]. The resulting annual set of data is representative of long-term weather patterns and is commonly used as input to predict average long-term thermal behaviour in building energy simulations. In Lisbon, the dataset is a synthetic interpolation of 30 years of weather data [15], while in Porto and Faro the original dataset includes 18 years of weather recordings [16]. All three data files were obtained from the EnergyPlus website [17]. The weather data showed that winter is mild in all three cities, which leads to low heating needs. On the other hand, summer is warm in Porto ( $C s b$ in the Köppen-Geigen climate classification) and hot in both Lisbon and Faro (Csa) $[18,19]$. In these latter two cities, cooling needs were expected to be higher while the potential for ventilation-based cooling was expected to be lower than in Porto.

The building simulation model was based on the Medium Office Model of the standard United States Department of Energy Commercial Reference Buildings dataset [20]. A few changes were required to improve the original model's passive thermal behaviour, i.e., the addition of shading fins and low-emissivity double-glazing windows. Despite originating from a US dataset, the model's thermal behaviour fully complied with Portuguese building regulations [21]. HVAC was modelled to supply the required airflow levels [22] and to ensure standard thermal comfort conditions [23]. Additionally, the original model's floor plan was altered to that shown in Figure 2, allowing the office spaces to be fully naturally ventilated [22]. Finally, equipment, lighting and occupation levels followed typical or regulatory values [22,24-26]. 


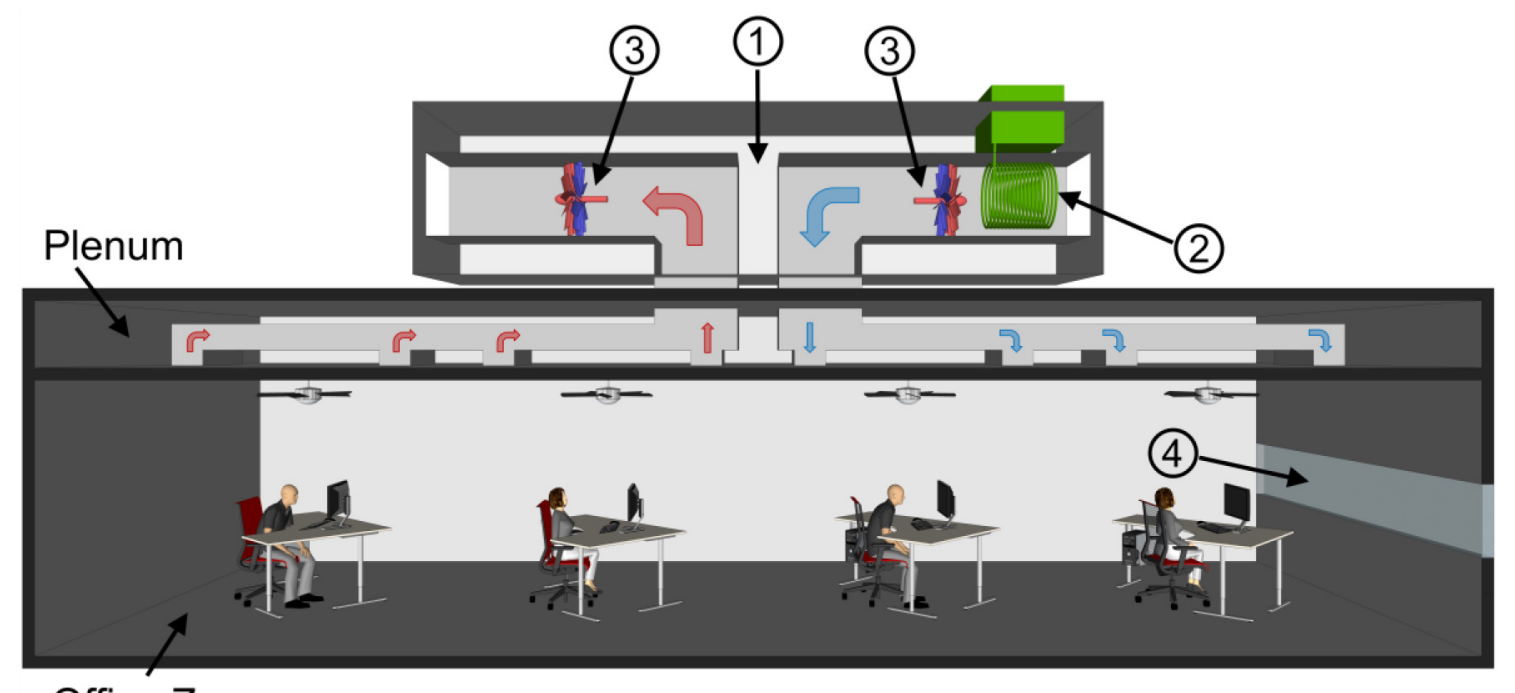

Office Zone

Fig. 3. HVAC layout: (1) Rooftop air handling unit; (2) Heat pump and heat exchanger; (3) Fans; (4) Window.

The simulation model consisted of a single building level, with the floor and ceiling plates connected in order to create a periodic boundary condition. Assuming a wellinsulated top floor, this conservative approach simplifies the simulation at the expense of foregoing detailed analysis of the top and bottom floors [27]. For the purpose of this study, the building consisted of ten identical levels.

The building model's HVAC system consisted of an air-handling unit (AHU), with an integrated heat pump, shown schematically in Figure 3 . This system keeps the indoor temperature between 20 and $26^{\circ} \mathrm{C}$ [23] during building operation times, namely weekdays between 0800 and 1800 [25]. At night, as well as during weekends and holidays, the AHU was shut off. For each time step, the EnergyPlus simulation model calculated a heating or cooling load to be supplied by the AHU to each thermal zone.

Four H\&C technology scenarios were considered:

- (1) ASHP: a generic air-source heat pump exchanging heat with the outside air.

- (2) GSHP: A ground-source heat pump, with similar characteristics to that of Scenario (1), was used, to exchange heat with the ground, through energy piles.

- (3) ASHP-NV hybrid: NV was used to reduce the cooling load; the ASHP was used to supply the remaining cooling and the heating;

- (4) GSHP-NV hybrid: as with Scenario (3), NV decreased the cooling load and the heat pump (GSHP) supplied the remaining cooling and heating.

For each of these scenarios, the thermal load was assumed to be independent of the type of heat pump. However, the final energy (electricity) use by the heat pumps (shown in light green, in Fig. 1) was not and, therefore, required computation of heating and cooling COPs, which are described below. To this electricity consumption, a further $10 \%$ was added, to include power consumption of the distribution pumps in the total H\&C-related energy use [28].
Table 1. Heat pump fluid temperatures.

\begin{tabular}{lll}
\hline Temperature & Heating & Cooling \\
\hline $\begin{array}{l}\text { Distribution } \\
T_{\text {dist }}\left[{ }^{\circ} \mathrm{C}\right]\end{array}$ & 45 & 5 \\
Condenser & $T_{\text {dist }}+5$ & $T_{\text {out }}+5$ \\
$T_{\text {cond }}\left[{ }^{\circ} \mathrm{C}\right]$ & $T_{\text {out }}-5$ & $T_{\text {dist }}-5$ \\
Evaporator & & \\
$T_{\text {evap }}\left[{ }^{\circ} \mathrm{C}\right]$ & & \\
\hline
\end{tabular}

\subsection{Scenario (1): air-source heat pump}

The ASHP was modelled as a generic heat pump, i.e., its COP was defined as a function of the condenser and evaporator temperatures as well as its efficiency $(\psi)$, as seen in equations (1) and (2) [10-12,28]. This efficiency is defined as the ratio between the heat pump's actual COP and that of an ideal Carnot engine.

$$
\begin{aligned}
& C O P_{\text {heat }}=\psi_{\text {heat }} \times \frac{T_{\text {cond }}+273.15}{T_{\text {cond }}-T_{\text {evap }}} \\
& C O P_{\text {cool }}=\psi_{\text {cool }} \times \frac{T_{\text {evap }}+273.15}{T_{\text {cond }}-T_{\text {evap }}}
\end{aligned}
$$

Post-simulation analysis was used to compute the necessary heating or cooling COPs, at each time step, to be applied to the respective simulation thermal load outputs. Fluid distribution temperatures were defined as set values, for heating and for cooling. The condenser and evaporator temperatures were dependent on the fluid distribution and on the outdoor air temperatures of the TMY weather file, as shown in Table 1 [28]. The heat pump's efficiency was $40 \%$ in both heating and cooling modes [29]. 


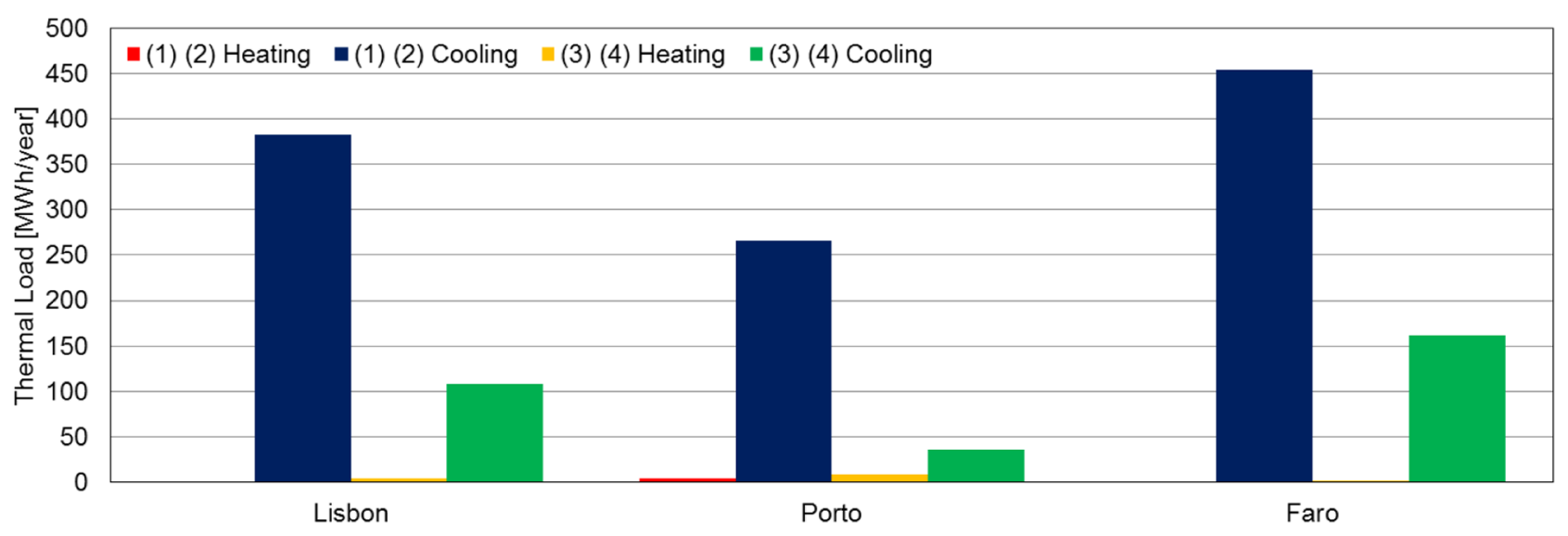

Fig. 4. Annual heating and cooling loads without NV (Scenarios (1) and (2)) and with NV (Scenarios (3) \& (4)).

\subsection{Scenario (2): ground-source heat pump}

The COP of the GSHP with piles was calculated with the pile heat exchanger modelling software PILESIM2.1 (presented in blue, in Fig. 1) [5,30], which applies a modified version of the Duct Ground Heat Storage Method (DST) [31]. This method models heat flow analytically between the heat exchangers and the storage volume (local heat flow) and through finite differences between the heat storage volume and the undisturbed ground (global heat flow). This hybrid analytical-numerical model is commonly considered a benchmark analysis tool due to its computational efficiency [32].

In this study, PILESIM2.1 used the EnergyPlus thermal load outputs, as shown in Figure 1, to calculate the heat pump's COP and the build-up in ground temperature, during long-term use of the HVAC system, which in this case was fifty years. For each year, the annual heating and cooling loads were assumed to be identical. The heat pump's efficiency and heating distribution temperature were identical to that of Scenario (1), specifically, $40 \%$ and $45{ }^{\circ} \mathrm{C}$, respectively. However, the cooling distribution fluid temperature was increased to $15^{\circ} \mathrm{C}$, a more typical value for GSHP [33]. All of the building's 27 foundation piles were used as heat exchangers, with a 4 -U tube pipe configuration. The piles were $30 \mathrm{~m}$ long and $90 \mathrm{~cm}$ in diameter, and were placed $8.5 \mathrm{~m}$ apart.

Excessive heat build-up in the ground can result in the heat carrier fluid in the energy piles reaching excessively high temperatures, which can potentially damage the heat pump, e.g., high-pressure failure in the compressor. In order to avoid equipment damage, a maximum temperature threshold of $50{ }^{\circ} \mathrm{C}$ was defined for the carrier fluid. Above this threshold, the GSHP is shut down and, therefore, unable to supply the full thermal load. The remaining load was considered to be covered by a supplementary ASHP, with the average COP obtained in Scenario (1) used to calculate its electricity consumption. Both the build - up of ground temperature and the fraction of thermal load that was covered by the GSHP were calculated with PILESIM2.1.

\subsection{Scenarios (3) and (4): natural ventilation}

Hybrid natural-mechanical ventilation was modelled in EnergyPlus. At each simulation time step, and for each of the four office thermal zones, if the outdoor temperature was above $10^{\circ} \mathrm{C}$ (to avoid overcooling [34]) and below that zone's air temperature, wind and buoyancy-driven NV was used [35], replacing the AHU and heat pump, which were subsequently turned off. During the unoccupied period (at night, weekends and holidays), when the AHU was inactive, NV was used, with the same temperature constraints, to pre-cool the building.

This hybrid approach decreases the annual cooling load, while leaving the heating load largely unaltered. These new loads are used as inputs to calculate the electricity use of Scenarios (3) and (4) per the methods described in Scenarios (1) and (2), respectively.

\section{Results and analysis}

\subsection{Energy performance}

Figure 4 summarizes the one-year H\&C loads calculated in EnergyPlus for the three locations considered under Scenarios (1) and (2), and, after the introduction of NV, under Scenarios (3) and (4).

Most of the thermal load (above 99\%) was for cooling, which decreased significantly with the introduction of NV to $87 \%$ in Porto, $72 \%$ in Lisbon and $64 \%$ in Faro. A slight increase in heating load also occurred, despite NV-use being designed to decrease the cooling load without altering the heating load. Although building thermal mass precooling reduced the cooling load of the first few hours of each day of building operation, internal heat sources (equipment, lighting and occupation) required a few time steps to start heating that thermal mass. The HVAC system was thus required to supply a very low albeit nonzero heating load during those time steps. Nonetheless, this variation in heating load had no significant effect on the total electricity needs for heating and cooling and could therefore be ignored. 
Table 2. COP for each scenario, fraction of thermal load covered by GSHP, and increase in ground temperature after 50 years of GSHP use.

\begin{tabular}{lllllll}
\hline City & Scenario & $\begin{array}{l}\text { Heating } \\
\text { COP }\end{array}$ & $\begin{array}{l}\text { Cooling } \\
\text { COP }\end{array}$ & $\begin{array}{l}\text { Heating Load } \\
\text { Covered }\end{array}$ & $\begin{array}{l}\text { Cooling Load } \\
\text { Covered }\end{array}$ & $\begin{array}{l}\Delta \mathrm{T} \text { Ground } \\
{\left[{ }^{\circ} \mathrm{C}\right]}\end{array}$ \\
\hline \multirow{5}{*}{ Lisbon } & $(1)$ & 2.51 & 3.65 & - & - & - \\
& $(2)$ & 4.34 & 3.32 & $100 \%$ & $72 \%$ & 23.4 \\
& $(3)$ & 2.71 & 3.14 & - & - & - \\
& $(4)$ & 4.28 & 4.14 & $100 \%$ & $100 \%$ & - \\
Porto & $(1)$ & 2.45 & 4.15 & - & - & 20.9 \\
& $(2)$ & 4.17 & 3.77 & $100 \%$ & $94 \%$ & - \\
& $(4)$ & 2.59 & 3.69 & - & - & - \\
\multirow{5}{*}{ Faro } & $(1)$ & 4.17 & 6.10 & $100 \%$ & - & 23.6 \\
& $(2)$ & 2.55 & 3.62 & - & $60 \%$ & - \\
& $(3)$ & 4.15 & 3.20 & $100 \%$ & - & 12.1 \\
\hline
\end{tabular}

Table 2 shows the heating and cooling COPs for the heat pump in each scenario. For Scenarios (2) and (4), the $\mathrm{COP}$ refers only to the GSHP and its respective fraction of covered thermal load. This fraction is also indicated in the same table (with the remainder being covered by a supplementary ASHP, as previously indicated) as well as the increase in ground temperature after 50 years. In heating mode, the GSHP could always provide $100 \%$ of the load. Additionally, as the ground temperature was typically higher than the air temperature (and further increased by the build-up of heat in the ground), the heating COP was higher in the GSHP scenarios than for the ASHP scenarios. Further, the difference in heating COP in both GSHP Scenarios ((2) and (4)) was insignificant, while a slight increase was observed between the Scenarios (1) and (3), which was a consequence of the slight increase in heating load which coincided, on average, with slightly higher outdoor temperatures.

In cooling mode, comparing Scenarios (1) and (3) showed a decrease in COP. Although NV significantly decreased the cooling load, it could not be used to provide cooling when the outdoor temperature was too high. These high temperatures decreased the cooling COP.

The cooling COP for Scenario (2) was 9-12\% lower than for Scenario (1). The GSHP's higher cooling fluid distribution temperature would be expected to lead to a higher COP. However, this was countered by the build-up of heat in the ground, which over the 50 years of operation, increased the ground temperature by $20.9^{\circ} \mathrm{C}$ in Porto, $23.4{ }^{\circ} \mathrm{C}$ in Lisbon and $23.6{ }^{\circ} \mathrm{C}$ in Faro. This led to increasingly inefficient operation of the GSHP system, as well as resulting in the GSHP shutting down to avoid overheating of the heat carrier fluid and only partially supplying the cooling load: $94 \%$ in Porto, $72 \%$ in Lisbon and $60 \%$ in Faro. Shutting the GSHP down allowed the ground to dissipate some of the accumulated heat, but resulted in an unpredictable relationship between the ground temperature and COP of the GSHP.

To maintain groundwater quality, a number of northern European countries regulate the changes in groundwater temperature that can be caused by GSHP operation. Typically, the temperature is required to stay within a range of 5 to $25^{\circ} \mathrm{C}$, with acceptable temperature changes limited to 5 to $10^{\circ} \mathrm{C}$ [36]. If significant groundwater resources were associated with the developments considered here, it is likely that the cooling load serviced by the GSHP would need to be regulated to maintain groundwater temperatures at acceptable levels, though these limits may differ in the Portuguese climate.

Despite a decrease of between approximately half and two-thirds of that in Scenario (2), heat build-up in the ground was still significant in Scenario $(4): 7.7^{\circ} \mathrm{C}$ in Porto, $11.6^{\circ} \mathrm{C}$ in Lisbon and $12.1^{\circ} \mathrm{C}$ in Faro. These temperature changes were more in line with the typical regulated values noted above, though the absolute maximum ground temperature might restrict the cooling load that can be supplied. In Lisbon and Porto, this scenario allowed full coverage of the cooling thermal load, and resulted in the highest cooling COP. In Faro, however, the cooling COP was still lower than that of Scenario (1), but higher than that of Scenarios (2) and (3). Further, buildup of heat in the ground still did not allow the GSHP to supply the full cooling load in Faro, although the fraction of covered load increased from $60 \%$, in Scenario (2), to $82 \%$.

\subsection{Electricity consumption}

Figure 5 presents the average annual electricity consumption for all scenarios. In Scenarios (2) and (4), this annual electricity consumption was the average consumption over the 50-year energy pile simulation. In Scenarios (1) and (3), 


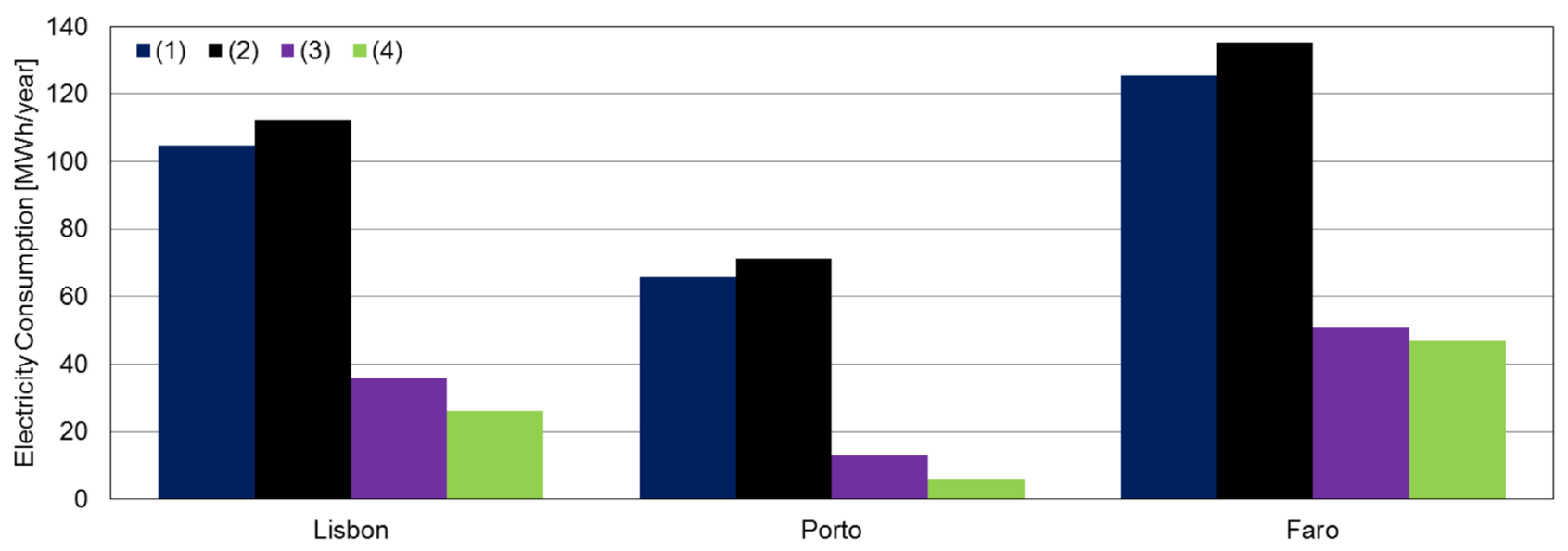

Fig. 5. Average annual electricity loads for all scenarios.

the results were directly calculated for a single year. In all scenarios, the minor variations in heating load and in heating COP did not significantly affect the annual electricity needs, which were primarily altered due to the decrease in cooling load, which resulted from the use of $\mathrm{NV}$, and the changes in cooling COP of each scenario.

The lower cooling COP of Scenario (2) led, unsurprisingly, to a $7-8 \%$ increase in average annual electricity consumption, relative to Scenario (1). However, this increase was limited by the backup use of the ASHP, which had a higher average cooling COP, to supply the load that the GSHP was unable to. In Scenario (3), the hybrid NV-ASHP HVAC approach decreased electricity consumption by $59 \%$ in Faro, $66 \%$ in Lisbon and $80 \%$ in Porto. It must be noted that the decrease in electricity consumption was lower than the decrease in thermal load, due to the lower cooling COP for this scenario. In Scenario (4), cooling COPs were higher than in Scenario (3), resulting in a further decrease in average annual electricity consumption to $62 \%$ in Faro, $74 \%$ in Lisbon and $88 \%$ in Porto, relative to Scenario (1). When compared to Scenario (3), the decrease was $7 \%, 25 \%$ and $39 \%$ respectively.

\section{Conclusions}

This study proposed a hybrid NV-GSHP system to improve HVAC energy efficiency in cooling-dominated commercial buildings in three Portuguese cities: Lisbon, Porto and Faro. Building simulations were used to compare this approach to three other solutions: ASHP, GSHP with piles and hybrid NV-ASHP.

Results showed that without the hybridization of NV, the use of GSHP with piles could not completely provide the required cooling load and led to a significant build-up of heat in the ground $\left(18.9-25.1^{\circ} \mathrm{C}\right.$ over 50 years), which reduced the heat pump's cooling $\mathrm{COP}$, increasing the average annual electricity consumption. In the case of the heating load, the heat pump's COP increased, further decreasing the already insignificant contribution of heating to the overall use of electricity.
The use of NV decreased the required cooling load by 64-87\%. When combined with an ASHP, the heat pump was still required when the outdoor temperature was too high for NV cooling, although these high temperatures decreased the heat pump's COP. In this scenario, total electricity use was reduced by $59-80 \%$.

Finally, the combined use of NV and GSHP with piles decreased total electricity use by $62-88 \%$. Nonetheless, in Faro, the warmest of the analysed cities, this hybrid system still could not supply $100 \%$ of the cooling load. The imbalance between heating and cooling loads was diminished with the use of $\mathrm{NV}$, which decreased the build-up of ground temperature $\left(5.7-13.6^{\circ} \mathrm{C}\right.$, over 50 years).

The build-up of heat in the ground due to unbalanced cooling loads will be the focus of future work. Other optimization approaches can also be considered, such as an enhanced management of the heat flows between the ASHP and the GSHP or the addition of alternative or additional hybridization technology, such as cooling towers or dryfluid cooling. However, the decrease in energy consumption and increase in overall efficiency showed that the use of a hybrid NV-GSHP with piles HVAC system should be considered in some cooling-dominated scenarios.

Acknowledgments. The post-doctoral fellowship of the first author and the work developed in this communication are part of the research project DEEPCOOL (PTDC/ECI-EGC/29083/2017) which is funded by the Foundation for Science and Technology (FCT), Portugal. The authors are grateful for this financial support.

\section{References}

1. C. Chen, B. Zhao, Review of relationship between indoor and outdoor particles: I/O ratio, infiltration factor and penetration factor, Atmos. Environ. 45, 275-288 (2011)

2. D.A. Chwieduk, Towards modern options of energy conservation in buildings, Renew. Energy 101, 1194-1202 (2017)

3. I. Sarbu, C. Sebarchievici, General review of ground-source heat pump systems for heating and cooling of buildings, Energy Build. 70, 441-454 (2014) 
4. P.J. Bourne-Webb, T.M. Bodas Freitas, Thermally-activated piles and pile groups under monotonic and cyclic thermal loading - a review, Renew. Energy 147, 2572-2581 (2020)

5. J. Fadejev, R. Simson, J. Kurnitski, F. Haghighat, A review on energy piles design, sizing and modelling, Energy 122, 390-407 (2017)

6. Y. Man, H. Yang, J. Wang, Study on hybrid ground-coupled heat pump system for air-conditioning in hot-weather areas like Hong Kong, Appl. Energy 87, 2826-2833 (2010)

7. W. Zhang, J. Wei, Analysis on the soil heat accumulation problem of ground source heat pump system in high temperature and high humidity areas, Energy Proc. 14, 198-204 (2012)

8. Z. Liu, Y. Li, W. Xu, H. Yin, J. Gao, G. Jin, L. Lun, G. Jin, Performance and feasibility study of hybrid ground source heat pump system assisted with cooling tower for one office building based on one Shanghai case, Energy 173, 28-37 (2019)

9. K.F. Beckers, G.A. Aguirre, J.W. Tester, Hybrid groundsource heat pump systems for cooling-dominated applications: experimental and numerical case-study of cooling for cellular tower shelters, Energy Build. 177, 341-350 (2018)

10. N.R. Martins, G. Carrilho da Graça, Impact of outdoor PM2.5 on natural ventilation usability in California's nondomestic buildings, Appl. Energy 189, 711-724 (2017)

11. N.R. Martins, G. Carrilho da Graça, Simulation of the effect of fine particle pollution on the potential for natural ventilation of non-domestic buildings in European cities, Build. Environ. 115, 236-250 (2017)

12. N.R. Martins, G. Carrilho da Graça, Effects of airborne fine particle pollution on the usability of natural ventilation in office buildings in three megacities in Asia, Renew. Energy 117, 357-373 (2018)

13. D.B. Crawley, L.K. Lawrie, F.C. Winkelmann, W.F. Buhl, Y. Joe Huang, C.O. Pedersen, R.K. Strand, R.J. Liesen, D.E. Fisher, M.J. Witte, J. Glazer, EnergyPlus: creating a newgeneration building energy simulation program, Energy Build. 33, 319-331 (2001)

14. J. Bravo Dias, G. Carrilho da Graça, P.M.M. Soares, Comparison of methodologies for generation of future weather data for building thermal energy simulation, Energy Build. 206, 109556 (2020)

15. R. Aguiar, INETI Synthetic Weather Data for Portugal. Instituto Nacional de Engenharia, Tecnologia e Inovação (INETI), 2005

16. ASHRAE, International Weather for Energy Calculations (IWEC Weather Files) Users Manual and CD-ROM, in American Society of Heating, Refrigerating, and Air Conditioning Engineers, Inc., Atlanta, GA, United States, 2001

17. Weather Data | EnergyPlus, https://energyplus.net/weather [last accessed August 2021]

18. M. Kottek, J. Grieser, C. Beck, B. Rudolf, F. Rubel, World map of the Köppen-Geiger climate classification updated, Meteorologische Zeitschrift 15, 259-263 (2006)

19. F. Rubel, K. Brugger, K. Haslinger, I. Auer, The climate of the European Alps: Shift of very high resolution KöppenGeiger climate zones 1800-2100, Meteorologische Zeitschrift 26, 115-125 (2017)

20. M. Deru, K. Field, D. Studer, K. Benne, B. Griffith, P. Torcellini, B. Liu, M. Halverson, D. Winiarski, M. Rosenberg,
M. Yazdanian, J. Huang, D. Crawley, U. S. Department of Energy Commercial Reference Building Models of the National Building Stock, National Renewable Energy Laboratory, NREL/TP-5500-46861 (2011)

21. Portaria n. ${ }^{\circ} 349-\mathrm{D} / 2013$ (2013)

22. California Building Standards Commission, Title 24-Building Standards Code, Part 4-California Mechanical Code, California Code of Regulations (2013)

23. International Organization for Standardization, ISO 7730:2005 Ergonomics of the thermal environment Analytical determination and interpretation of thermal comfort using calculation of the PMV and PPD indices and local thermal comfort criteria (2005)

24. J. Johnston, J. Counsell, P.A. Strachan, Trends in Office Internal Gains and the Impact on Space Heating and Cooling. CIBSE Technical Symposium, DeMontfort University, Leicester, UK (2011)

25. J. Zhao, B. Lasternas, K.P. Lam, R. Yun, V. Loftness, Occupant behavior and schedule modeling for building energy simulation through office appliance power consumption data mining, Energy Build. 82, 341-355 (2014)

26. ASHRAE, ASHRAE Handbook - Fundamentals. American Society of Heating, Refrigerating, and Air Conditioning Engineers, Inc., Atlanta, GA, United States (2013)

27. M. Malato Lerer, G. Carrilho da Graça, P.F. Linden, Building energy demand response simulation for an office tower in New York, in Proceedings of BS2013: 13th Conference of International Building Performance Simulation Association, Chambéry, France (2013), p. 2511-2518

28. G. Carrilho da Graça, N.R. Martins, C.S. Horta, Thermal and airflow simulation of a naturally ventilated shopping mall, Energy Build. 50, 177-188 (2012)

29. I.S. Ertesvåg, Uncertainties in heat-pump coefficient of performance (COP) and exergy efficiency based on standardized testing, Energy Build. 43, 1937-1946 (2011)

30. D. Pahud, PILESIM2-simulation tool for heating/cooling systems with energy piles or multiple borehole heat exchangers - user manual, in ISAAC-DAC-SUPSI, Lugano, Switzerland (2007)

31. G. Hellström, Duct Ground Heat Storage Model, Manual for Computer Code, Department of Mathematical Physics, University of Lund, Sweden (1989)

32. M. Fossa, F. Minchio, The effect of borefield geometry and ground thermal load profile on hourly thermal response of geothermal heat pump systems, Energy 51, 323-329 (2013)

33. J.M. Corberan, D.P. Finn, C.M. Montagud, F.T. Murphy, K.C. Edwards, A quasi-steady state mathematical model of an integrated ground source heat pump for building space control, Energy Build. 43, 82 (2011)

34. S. Herkel, U. Knapp, J. Pfafferott, Towards a model of user behaviour regarding the manual control of windows in office buildings, Build. Environ. 43, 588-600 (2008)

35. P.R. Warren, The analysis of single-sided ventilation measurements, Air Infiltration Rev. 7, 3-5 (1986)

36. S. Hähnlein, P. Bayer, G. Ferguson, P. Blum, Sustainability and policy for the thermal use of shallow geothermal energy, Energy Policy 59, 914-925 (2013)

Cite this article as: Nuno R. Martins, Peter J. Bourne-Webb, Hybridization of Heat Pump Systems With Natural Ventilation To Improve Energy Efficiency in Cooling Dominated Buildings, Renew. Energy Environ. Sustain. 6, 33 (2021) 